\title{
La iglesia del Sagrado Corazón de Jesús en Elche. Un ejemplo de la introducción del hormigón en la arquitectura sacra
}

\author{
Silvia Spairani Berrio \\ Miguel Louis Cereceda \\ Yolanda Spairani Berrio \\ José Antonio Huesca Tortosa \\ Universidad de Alicante
}

\section{RESUMEN}

La iglesia del Sagrado Corazón de Jesús (Alicante, España), es quizás, el edificio proyectado por el arquitecto D. Antonio Serrano Peral cuyo valor arquitectónico es menos conocido y reconocido en el ámbito de la historia de la arquitectura de la ciudad. Sin embargo, su construcción constituye un interesante ejemplo de arquitectura sacra, como reconoció el jurado del Ministerio de Educación Nacional en 1957, en la exposición nacional de bellas artes, al conceder al arquitecto la medalla de primera clase en la sección de Arquitectura por la citada obra. Al analizar la historia de la construcción de la iglesia y sus sistemas constructivos se detecta que el trazado de la planta sigue el modelo arquitectónico de cruz griega de Santa Sofía y que la cúpula introduce el hormigón, conviviendo con mampostería y fábrica de ladrillo.

\section{PALABRAS CLAVE:}

Arquitectura sacra, patrimonio histórico, materiales de construcción, hormigón.

\section{ABSTRACT}

The church of Sagrado Corazón de Jesús located in Elche (Alicante, Spain) is perhaps the building designed by the architect Antonio Serrano Peral whose architectonic value is least well-known and least recognized in the field of the architectural history of the city, as it should have had. However, its construction is an interesting example of religious architecture, being recognized by the jury of the Ministry of National Education in 1.957 at the National Exhibition of Fine Arts, where the architect was prized with the first class medal in the architecture section, due to the mentioned design. Thanks to the analysis of the church s building history and the used construction s systems, it is detected that the layout of the floor is based on the Greek cross constructive model of Santa Sofia, detecting also the introduction of concrete in the Byzantine dome, getting along with masonry and brick factory.

\section{KEY WORDS:}

Sacred architecture, historical heritage, building materials, concrete. 
Antonio Serrano Peral y la adaptación de la ciudad de Elche a las nuevas condiciones de su crecimiento durante el siglo XX

Sin duda, el hecho de haber obtenido el 25 de Junio de 1935 el título de Arquitecto por la Escuela Superior de Madrid y desde ese mismo momento actuar como Arquitecto Suplente de Elche, nos ofrece la oportunidad idónea para un ejercicio de reflexión y de valoración de un hombre, trabajador incansable, que ha tenido gran importancia en la creación de la moderna imagen de la ciudad de Elche, destacándose sus obras de carácter religioso, viviendas, equipamientos $\mathrm{y}$ edificios industriales.

Aparejador y arquitecto de formación, la figura deAntonio Serrano Peral (1907-1968), va bastante más allá de esta capacitación profesional, que ejerció, por otra parte con gran competencia. D. Antonio Serrano Peral aparece también, como un servidor público comprometido, desde diversas instancias e instituciones- entre las cuales destacar por su labor sus aportaciones: al Instituto Nacional de la vivienda sobre arquitectura rural, como Presidente de la Comisión de Arte Sacro y obras del Obispado de Orihuela; y como Vocal:de la Junta para la construcción del Templo del Sagrado Corazón de Jesús, de la Junta Diocesana de Reconstrucción tanto de Templos Parroquiales como del Misterio de Elche, de la Comisión Provincial de Monumentos Histórico-Artísticos o de la Comisión Provincial de Servicios Técnicos de la Diputación Provincial de Alicante ${ }^{1}$.Finalmente, aunque con menor entidad, y no por ello menos importante, aparece como urbanista que considera el contexto de la ciudad, proponiendo una arquitectura integrada y vinculada a la defensa de los Palmerales de la ciudad ${ }^{2}$.

Tenemos que entender que el Arq. D. Antonio Serrano Peral proyectó a lo largo de su ejer-

1 CANDELA GARRIGÓS, Ma R., Antonio Serrano Peral, un arquitecto ilicitano (1928-1968), Atrio, Revista de Historia del Arte, $n^{\circ}$ 1, Universidad de Sevilla, 1989, pp.61-63.

2 Entre sus actuaciones se destacan los ajardinamientos significativos de huertos de palmeras emblemáticos en la ciudad de ilicitana como el Hort del Colomer (1946), el Hort del Xocolater (hacia 1955) y el Hort del Gat (hacia 1965). JAEN i URBAN, G., Antonio Serrano Peral (19071968),Actas del I Congreso nacional Pioneros de la arquitectura moderna española: vigencia de su pensamiento y obra. Madrid: Fundación Alejandro de la Sota, 2014. pp. 440-441

JAEN i URBAN, G.,Guía de l'arquitectura i l'urbanisme de la ciutat d'Elx, Vol. I, Colegio Oficial de Arquitectos de la Comunidad Valenciana, Demarcación de Alicante, Conselleria de Cultura, Educació i Ciència, Ayuntamiento de Elche, Alicante, 1990, pp.142 y ss. cicio profesional obras de un estilo propio, caracterizado por la adaptación de diversas influencias ${ }^{3}$ : Art-Déco, oriental, arquitectura popular, academicista y movimiento moderno.

Nos parece importante destacar que en el periodo de madurez del Arquitecto (1940-1955), ciclo más amplio y productivo de su carrera, surgiera la inminente necesidad del desarrollo de arquitectura religiosa de nueva plantaen las ciudades de Elche y Alicante. Lo cualprovocóun giro en la carrera del arquitecto, que dio lugar, a una dedicación más intensa hacia ésta y ocasionó la disminución de proyectos de viviendas, equipamientos y edificios industriales. Entre sus obras de carácter religioso merece mención especial la primera Iglesia de nueva planta que el arquitecto realizó con estilo purista o depurado la Iglesia del Sagrado Corazón de Jesús ${ }^{4}$.

Dicha construcción cinco años después de haber finalizado, recibe la Primera Medalla de la Sección de Arquitectura ${ }^{5}$, del jurado del Ministerio de Educación Nacional, en la exposición nacional de Bellas Artes celebrada el 16 de mayo de 1957. Dicha distinción se le concede al arquitecto porque posiblemente el jurado consideró que pone en valor las necesidades eclesiásticas y estatales del momento, debido, a que la mirada en los diversos elementos recogidos del lenguaje popular y casticista (como rejas, celosías, tejas, y enlucidos)queda perfectamente integrada. Además, el arquitecto incluyó una sencillez ornamental, una pureza de líneas y de volumetría, tanto en el interior como en el exterior, que permitió combinar las necesidades religiosas de crecimiento con la preservación de los valores paisajísticos del entorno cercano, los valores históricos y los valores culturales del momento ${ }^{6}$.

Por eso, este artículo quiere hacer una interpretación sintética que nos permita descubrir el Proyecto original de la citada Iglesia delArq. D. Antonio Serrano Peral para poder contextualizar su obra, considerando tanto las ideas ra-

3 CANDELA GARRIGÓS, Ma R., Antonio Serrano Peral, un arquitecto ilicitano (1928-1968), Atrio, Revista de Historia del Arte, $\mathrm{n}^{\circ}$ 1, Universidad de Sevilla, 1989, pp.64-65.

4 CANDElA GARRIGÓS, Ma R., Antonio Serrano Peral (Tesis de licenciatura), Universidad de Sevilla, 1987, pp.64.

5 Ver al respecto, la nota de prensa. "Concesión de los premios de la exposición nacional de bellas artes" $A B C$, 18$\mathrm{V}-1957: 46$

6 CANDELA GARRIGÓS, Ma R., "La obra arquitectónica de Antonio Serrano Peral(1928-1968)"en AA.VV. Ayudas a la investigación 1986-1987. Volumen III. Arqueología, Arte, Toponimia, Instituto de Cultura Juan Gil Albert, Alicante, 1990, pp. 136-138.

FALCO PÉREZ, P., MONTENEGRO ORS, M., Elx, El Ciutadà, tomo II, Artelibro, San Vicente, 1995, pp.257-258. 
cionalistas referentes a la organización de las plantas como las disposiciones de las fachadas (con líneas rectas y planos ausentes de ornamentación). Revelándose así, los valores de su idea de movimiento moderno en la arquitectura religiosa de la ciudad ilicitana.

\section{Un proyecto valioso e innovador de arquitec-} tura convertido en una gran realidad urbana

La construcción de la Iglesia del Sagrado Corazón de Jesúsincluida en el catálogo Municipal de edificios protegibles del 1982, con el núm. D38 , está fechada en mayo de $1947^{7}$. El proyecto se ubicó en el centro de la plaza de España llevándose a cabo entre el 11 de mayo de $1.947^{8} \mathrm{y}$ el 18 de junio de $1.952^{9}$. Aproximadamente a mitad de su construcción, el 21 de octubre de $1949^{10}$, tuvo lugar el derrumbe de la cúpula de la iglesia según se dijopor la mala calidad del mortero de la época de la postguerra. Éste colapso estructural no tuvo consecuencias funestas para los trabajadores que la estaban construyendo pero si un derrumbamiento importante, lo que conllevó prácticamente a tener que iniciar la reconstrucción desde su inicio.

A efectos de planeamiento cumplió con el decreto de 1933 y, posteriormente, con las ordenanzas de la construcción de 1949 y las Ordenanzas adicionales a las generales de la construcción de 1951. Urbanísticamente se decidió que se ubicase junto a las carreteras de Aspe, formando parte de la inicial plaza de carácter recreativo y comercial destinada a la contratación de productos agrícolas. Toponímicamente el inicio del nombre popular de la plaza de España (cruce de las calles Marqués de Asprillas con la de José María Buck)se dio en 1947, con las obras de construcción de la Iglesia del Sagrado Corazón de Jesús ${ }^{11}$.

7 JAEN i URBAN, G., Elx, barris dels segles XVIII, XIX i XX: arquitectura i urbanisme, Vol. 4, Institut Alacantí de Cultura Juan Gil-Albert, 2015, pp.187- 189.

8 Archivo Municipal de Elche. Sig. 600, nº.12, Documento acreditativo de la colocación de la primera piedra de la Iglesia del Sagrado Corazón de Jesús.

9 Sin autor., Parroquia del Sagrado Corazón de Jesús de Elche 50 aniversario (1952-2002), Parroquia del Sagrado Corazón de Jesús de Elche, Elche, 2002, pp. 58-63.

10 FALCO PÉREZ, P., MONTENEGRO ORS, M., Elx, El Ciutadà, tomo II, Artelibro, San Vicente, 1995, pp.124.

11 CANDELA GARRIGÓS, M ${ }^{a}$ R., Antonio Serrano Peral (Tesis de licenciatura), Universidad de Sevilla, 1987, pp.328. Archivo Municipal de Elche. Reg. 268, nº.85, Cesión de terrenos en la Plaza de España, para la construcción de la Parroquia del Sagrado Corazón de Jesús.
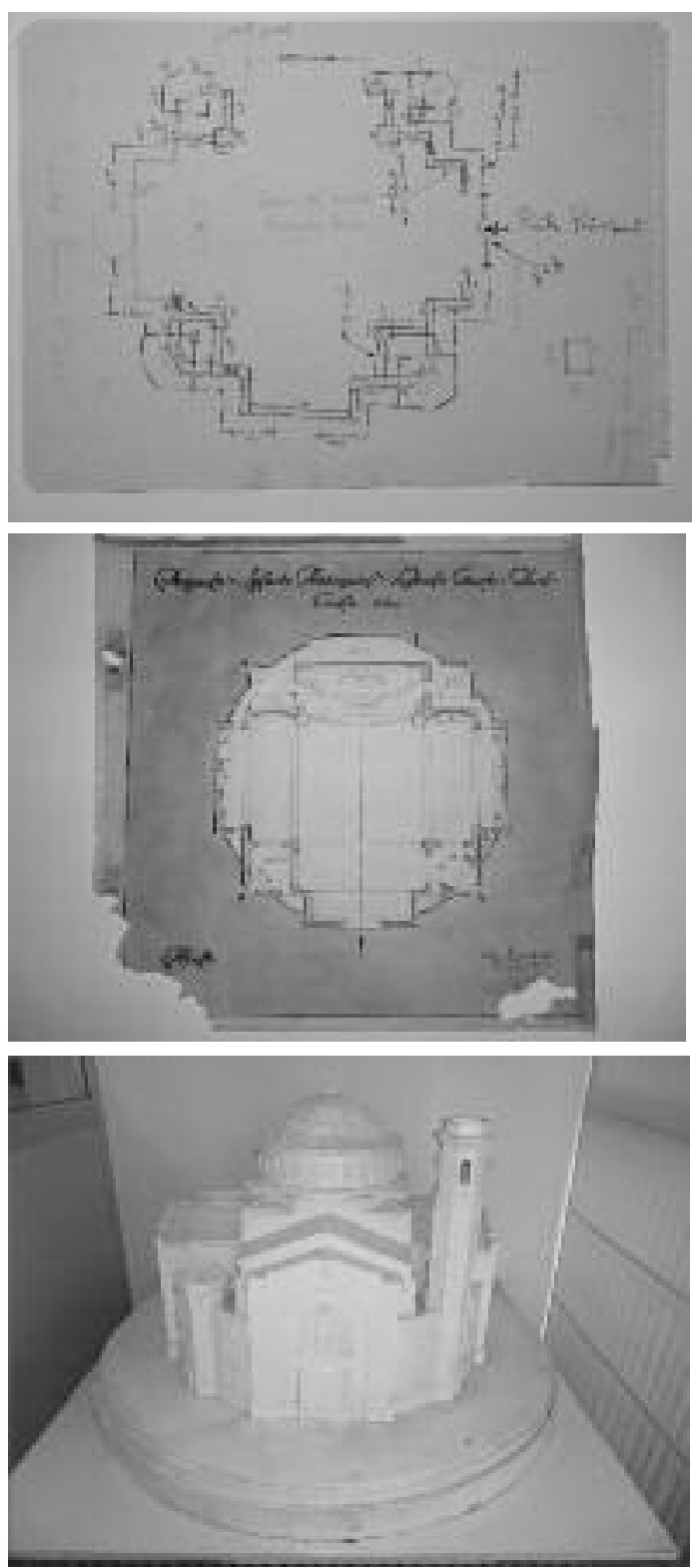

Fig. 1. Planta del proyecto (F1.1 y F.1.2) y maqueta original (F1.3) del arquitecto Antonio Serrano Peral. Fuente: colección Antonio Serrano Bru

Conviene así mismo, antes de entrar en el análisis de la descripción de la ejecución de las obras, que precisemos el estilo seguido por el Arq. D. Antonio Serrano Peral en la Iglesia del Sagrado Corazón de Jesús.Las fotografías conservadas y el proyecto original de volúmenes ligeros con geometrías puras, consultado en el archivo históricode su hijo el Arq. D. Antonio Serrano Bru, permiten ver que el proyecto original procuró adaptarse a las normas clásicas de la arquitectura del régimen de la postguerra.

El tratamiento constructivo incluyó las nuevas corrientes formales, de ahí que se proyectó y ejecutó un edificio religioso mucho más sen- 
cillo, más simétrico. Se está resaltando su valor más importante: estamos ante un muy buen ejemplo ilicitano de la primera etapa de la arquitectura moderna que puebla el territorio español. Comienzan a tomar vital importancia tanto la organización de las plantas como en la disposición de las fachadas, las líneas rectas y los planos ausentes de ornamentación, que se limitan a listeles rectilíneos o curvos. ${ }^{12}$ Siendo evidenteel surgimiento, en la ciudad ilicitana, de una nueva visión de arquitectura ${ }^{13}$ que hasta ese momento se había centrado en realizar una ciudad monumental barroca, como ejemplos se destaca la restauración de la basílica de Santa Maríao la reedificación de la iglesia del Salvador y de la iglesia de San Juan Bautista. Ciertamente, en ésta obra el arquitecto suprime la característica más significativa del barroco clásico en el sentimiento español ${ }^{14}$ que más identificaba España y por supuesto Elche, hasta principios de los años 40 del siglo XX.

Respecto a la descripción de la ejecución de las obras el arquitecto elige para el desarrollo del trazado de la planta de la iglesia una conformada por 3 figuras: un cuadrado, un círculo y una cruz griega, donde en este caso el cuadrado queda superpuesto con el círculo permitiendo que ligeramente sobresalgan y queden iguales los cuatro brazos, siguiendo el modelo de Santa Sofía de Estambul, ubicándose entre sus brazos las dependencias necesarias de una iglesia. Por supuesto, es crucial en el proyecto que en la cabecera del edificio se dé la intersección entre el cuadrado y la cruz griega para permitir originardos cuadrados, el lado derecho queda constituido por un cuerpo-ortogonal que alberga a la torre-campanario, y el lado izquierdo lo forma el baptisterio, tras este último se emplaza el despacho parroquial y el acceso a la sacristía. ${ }^{15}$ Por todo ello el diseño de la estructurapresentada que se adapta a su especial emplazamiento, en el interior de la plaza circular, da lugar a que la planta de la iglesia no se parezca a ninguna otra de las que existían en la ciudad de Elche en aquel entonces, y del resto de las proyectadas inicialmente ${ }^{16}$ por el ar-

12 Ver al respecto la nota de prensa. Camón Aznar, "Hacia una arquitectura nacional" $A B C, 20-I X-1947: 3$

13 Ver por ejemplo la iglesia del Salvador de Elche. CAÑESTRO DONOSO, A., Gloria pretérita. La parroquia de El Salvador de Elche. Segarra Sánchez, S.L, Elche, 2011, pp. 97-118

14 URRUTIA NÚÑEZ, Á., Arquitectura española del siglo XX. Madrid, 1997, pp.353 y ss.

15 CANDELA GARRIGÓS, Ma R., Antonio Serrano Peral (Tesis de licenciatura), Universidad de Sevilla, 1987, pp.328-330.

16 El estilo de esta nueva etapa será aplicada por el arquitecto en los siguientes templos religiosos: En Elche, la er- quitecto, caracterizándose ésta por su sencillez compositiva.

En el proyecto se apreciaunaplanta formada por una nave central con gran cúpula semiesférica, pero por fuera es rebajada, con arcos de medio punto en su base y tambor, completamente cerrada y comprimida que descansa directamente sobre pechinas molduradas sin decoración. Los brazos laterales se cubren con bóvedas de cañón con lunetos. Es un volumenque permite que se materialice un hipotético cuadrado sobre el que levantar cuatro construcciones en forma de torres octogonales prismáticas, unidas por paredes intermedias (Ver p. e. fig. 1) ${ }^{17}$.

Así, la limpia y moderna expresión de su plantaoctogonal y que forma un prisma liso secaracterizó por finalizar en 4 fachadas, donde contrasta que entres de ellas (las coincidentes con los transeptos de la iglesia),exista un formalismo de clara intención casticista y popular como se da en las cubiertas de teja roja que insistentemente se prodigan en el exterior, las rejas de las ventanas olos rosetonesde los brazos con celosía de motivos estrelladosque permite el paso de la luz hacia el interior del crucero de la iglesia.

El rasgo arquitectónico que más sorprende al exteriores que el complejo sistema de volúmenes variados alberga dos torres octogonales con cubiertas planas de diferentes alturas ${ }^{18}$, la pieza más baja se ubicó en el lado izquierdo de la puerta mayor quedando acostada y la del lado derecho dado que se destinó al uso de campanario, necesitó ser de mayor altura. En ambos lados de las torres encontramos dos ventanas simétricamente distribuidas y aseguradas con rejas de hierro forjado. Asimismo, es apreciable que en la base de estas cuatro torres prismáticas se abrieron tres puertas de acceso de los feligreses ${ }^{19}$, de simétrica construcción donde los

mita de San Crispín (1950) y la Iglesia del Salvador (1953); en Alicante la Iglesia de la Misericordia (1951), Iglesia de San Juan Bautista (1953-1960) e Iglesia de Nuestra Señora de los Ángeles (1954-1956) CANDELA GARRIGÓS, $M^{a}$ R., "La obra arquitectónica de Antonio Serrano Peral(1928-1968)"en AA.VV. Ayudas a la investigación 19861987. Volumen III. Arqueología, Arte, Toponimia, Instituto de Cultura Juan Gil Albert, Alicante, 1990, pp. 129.

17 Ibídem pp. 137 y Archivo de D. Antonio Serrano Peral.

18 Las torres recogen la tradición valenciana le otorgan esbeltez y se erige como elemento visual de referencia. CANDELA GARRIGÓS, Ma R., "La obra arquitectónica de Antonio Serrano Peral(1928-1968)"en AA.VV. Ayudas a la investigación 1986-1987. Volumen III. Arqueología, Arte, Toponimia, Instituto de Cultura Juan Gil Albert, Alicante, 1990, pp. 137.

19 Se aclara que la cuarta no presenta ningún acceso por destinarse al despacho parroquial. 
listeles horizontales y verticales son los únicos elementos ornamentales.

La fachada principal que recoge el ingreso al templo se ubica en lado Sur y presenta gran sencillez ornamental. La portada se enmarca en un amplio arco de medio punto en el que se ubica tanto el grupo escultórico en relieve diseñado por el autor (que no llegó a realizarse por la precariedad económica de la época), como el ingreso a través de una puerta revestida con madera y una chapa de hierro en su parte exterior.

El análisis de la planta ha permitido detectar que el acceso principal presentó una extraña orientación de su altar mayor, ubicado en la dirección Norte y no en la dirección Este de un templo cristiano de la época. Lo anterior fue debido, posiblemente, a que el arquitecto consideró facilitar el acceso de los fieles desde la parte con mayor densidad de población en el momento de la edificación.

Lo más significativo de su interior,además depresentar una gran sencillez ornamental reducida a listeles verticales y arcos de medio punto, es que el arquitecto no proyectó inicialmente la entreplanta y la planta coro(ver p. e. fig. 2) ${ }^{20}$. Se debe decir sin embargo, que si fueron necesarias y por ello el arquitecto decidió construirlasrepitiendo, de forma más liviana, los elementos de la planta inferior, rematando el conjunto con el acceso a los balcones y la hornacina protegida con cristal de Jesucristo de pie ${ }^{21}$ y con la colocación del órgano de la iglesia. En ambos casos tenemos una ampliación que mejora la obra sobre la que se interviene (ver p. e. fig. 3).

A efectos de nuestro estudio cuando se accedía a la nave central, a través de la puerta principal, se veía en el frente del altar mayor el presbiterio del templo. Éste estaba separado del resto de la nave mediante una grada y una barandilla adornada con cruces doradas, estando los laterales de la misma distribuida simétricamente con cuatro pequeños balcones, cerrados con postigos y una barandilla de hierro, como resultado de los ángulos formados por la unión de la nave central y el crucero de la iglesia.

A nivel intermedio de la planta baja y de la planta coro hay también que mencionar la ejecución de dos pulpitos consagradosa ambos lados del altar, inexistentes inicialmente en la sección de lafigura 2 y 3 . A estos últimos se accedía a través de las puertas laterales que unían la sa-

20 Archivo del Arq. D. Antonio Serrano Peral.

21 Sin autor., Parroquia del Sagrado Corazón de Jesús de Elche 50 aniversario (1952-2002), Parroquia del Sagrado Corazón de Jesús de Elche, Elche, 2002, pp. 81.


Fig. 2. Dibujo (F2.1) y sección original (F2.2) del proyecto del Arquitecto D. Antonio Serrano Peral. Fuente: colección Antonio Serrano Bru

cristía, las dependencias auxiliares y el presbiterio por su parte posterior. Quedarian todavía por reseñar que ambas plantas se pavimentaron con baldosa hidráulica, y que se resolvió el peldañeado de las escaleras de acceso interior mediante elementos prefabricados de cemento.

Sobre el presbiterio del altar mayor se sitúa un gran hueco rematado con arcos de medio punto, completándose el conjunto con basas para las imágenes de culto (ver p. e. fig. 3) 22 $^{22}$ La cuidadosa selección y el notable diseño del mismo unido a la adecuada escala del inmueble, imprime al conjunto una cierta simplicidad ornamental, pero sobre todo, evidencia una adaptación de los arcos de medio punto que materializaban las franjas que contenían figuras geométricas o relieves, de contextualización del culto religioso, un conocimiento del evangelio y un respeto hacia el mismo materializado en cinco relieves del evangelio: el cordero de Dios, la figura de Te-

22 Consultado el alzado correspondiente a la colección privada archivo del Arq. D. Antonio Serrano Peral y fotografía perteneciente a Sin autor., Parroquia del Sagrado Corazón de Jesús de Elche 50 aniversario (1952-2002), Parroquia del Sagrado Corazón de Jesús de Elche, Elche, 2002, pp. 88. 

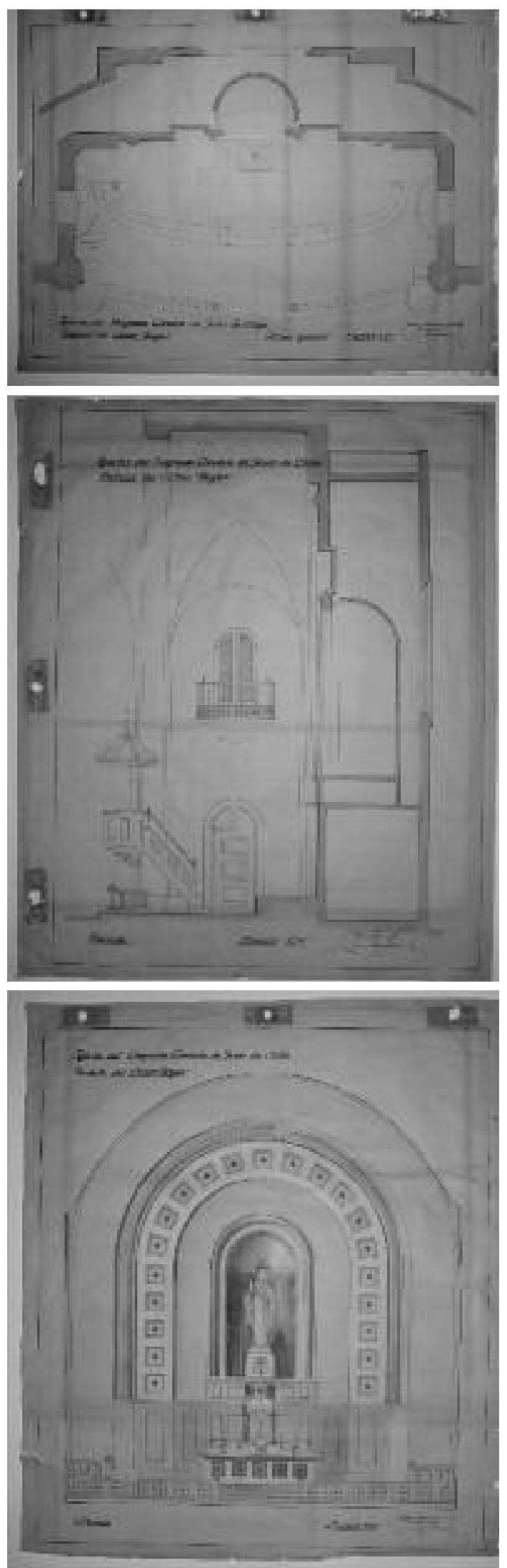

Fig. 3. Planta (F3.1), sección modificada (F3.2) y presbiterio del altar mayor (F3.3) del proyecto original del arquitecto. Fuente: colección Antonio Serrano Bru tramorfos, el águila de San Juan, el toro de San Mateo, el hombre de San Lucas y el león de San Marcos.

En la distribución interior de la nave central el autor introdujo la separación del presbiterio de la nave central mediante una grada y una barandilla o comulgatorio compuesto por cruces doradas. El resultado fue interesante aunque hoy en día no existe debido a que se intentó acercar más el presbiterio a los fieles en la reforma de $1995^{23}$.

Por otro lado, respecto a la descripción de la ejecución de las obras:el proyecto que se analiza comenzó con la explanación del solar en la plaza de España para, posteriormente, llevar a cabo el replanteo por el arquitecto director del edificio. Se destacaque: la cimentación se ejecutó con mampostería hormigonada y hormigón armado, de dosificación $200 \mathrm{~kg}$ y $150 \mathrm{~kg}$ de cemento respectivamente, siendo el trazado de la misma coincidente con la planta del edificio; los muros exteriores se ejecutaron con mampostería ordinaria de piedra franca careada tomada con mortero de cemento de 200 kgy fábrica de ladrillo hueco, ambas recibidas con mortero de cemento de 300 kgen paramentos. Hay también que indicar respecto a la construcción de los muros que se ejecutaron de forma que únicamente trabajarán a compresión, cuestión ésta que hizo que se limitase la altura de los mismos para evitar el pandeo. A efectos del proyecto dicha cuestión provocó que el arquitecto utilizara, muy acertadamente,en la estructura de ladrillo armado un mortero de $300 \mathrm{~kg}$ y en estructura de las correas o encadenados un mortero de 350 kgpara contrarrestar los posibles empujes asociados.

Posteriormente se procedió respecto a las bóvedas de la nave a resolverlas con ladrillo hueco de tres hojas tomado la primera hilado con yeso y las dos siguientes con mortero de cemento de $300 \mathrm{~kg}$.Cabe indicar que de igual forma que en la construcción de los muros se colocaron refuerzos que contrarrestasen los empujes horizontales que transmitieron los arcos de medio punto, bóvedas y cúpula central que conformaron el cerramiento de la nave utilizando un mortero de cemento de $350 \mathrm{~kg}$.

Una vez ejecutados los muros y pilares se procedió a la realización de los refuerzos de los empujes horizontales de los elementos abovedados, para ello se utilizaron elementos de hormigón

23 En el transcurso de los 56 años de vida del templo, la iglesia ha sufrido diversas transformaciones para adaptarla a las necesidades de cada momento. Todas las reformas fueron impulsadas por el Rvdn. D. Gines Román. 

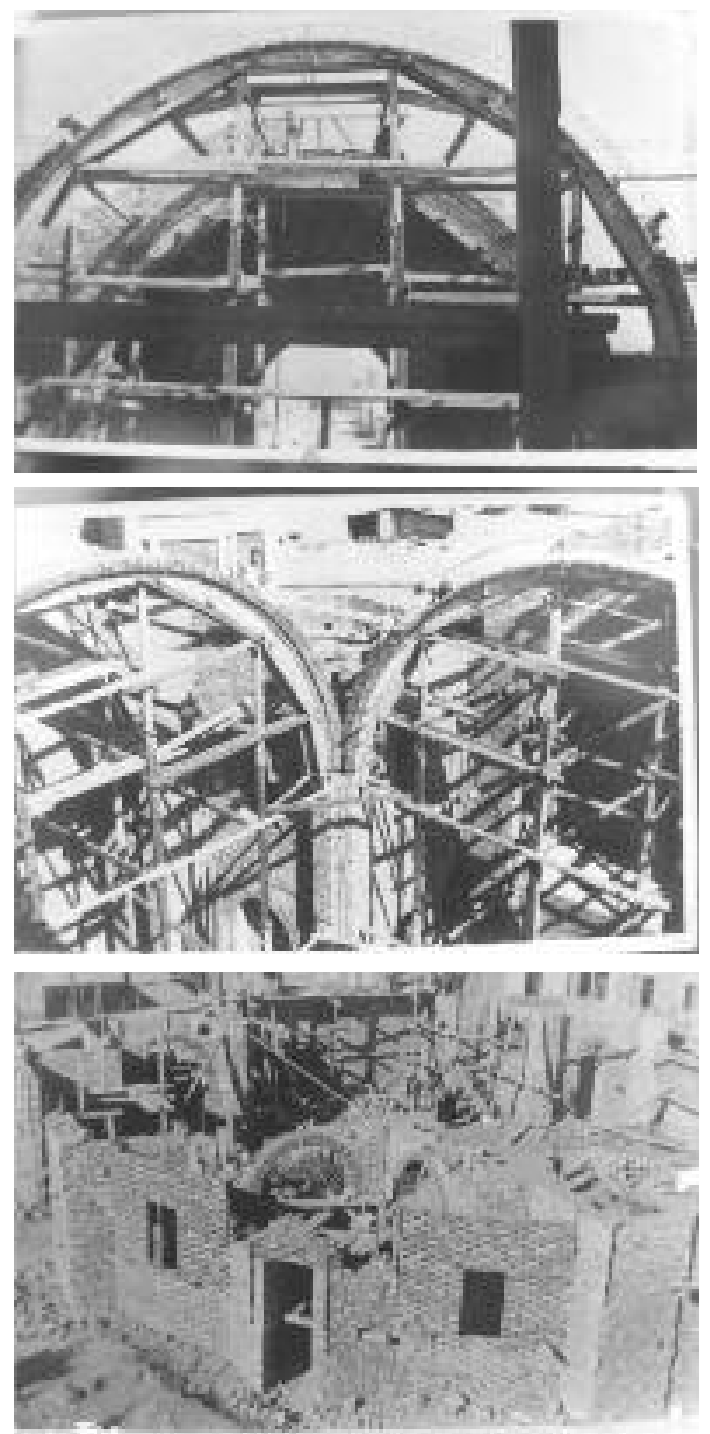

Fig. 4. Ejecución de los arcos fajones (F4.1, F4.2 y F4.3).

armado de $350 \mathrm{~kg}$ (Ver p. e. fig. 4) ${ }^{24}$. A continuación, se realizaron los arcos torales, mediante el empleo de cimbras de madera comenzando a levantarse por los arranques o salmeres. Las bóvedas de cañón se ejecutaron mediante la disposición de arcos de medio punto adosados unos a otros, para ello se fue desplazando la cimbra de madera.Para absorber el empuje horizontal de estos elementos se rellenó con hormigón armado el primer tercio de la flecha inferior con lo que se trasladaron las cargas y los empujes que sobre ellos gravitaban a los apoyos, quedando las bóvedas tabicadas de ladrillo hueco como elemento estructural.

24 Todas las figuras que se muestran a continuación de la fase de ejecución de la construcción pertenecen a la colección privada del archivo del Arq. D. Antonio Serrano Peral.
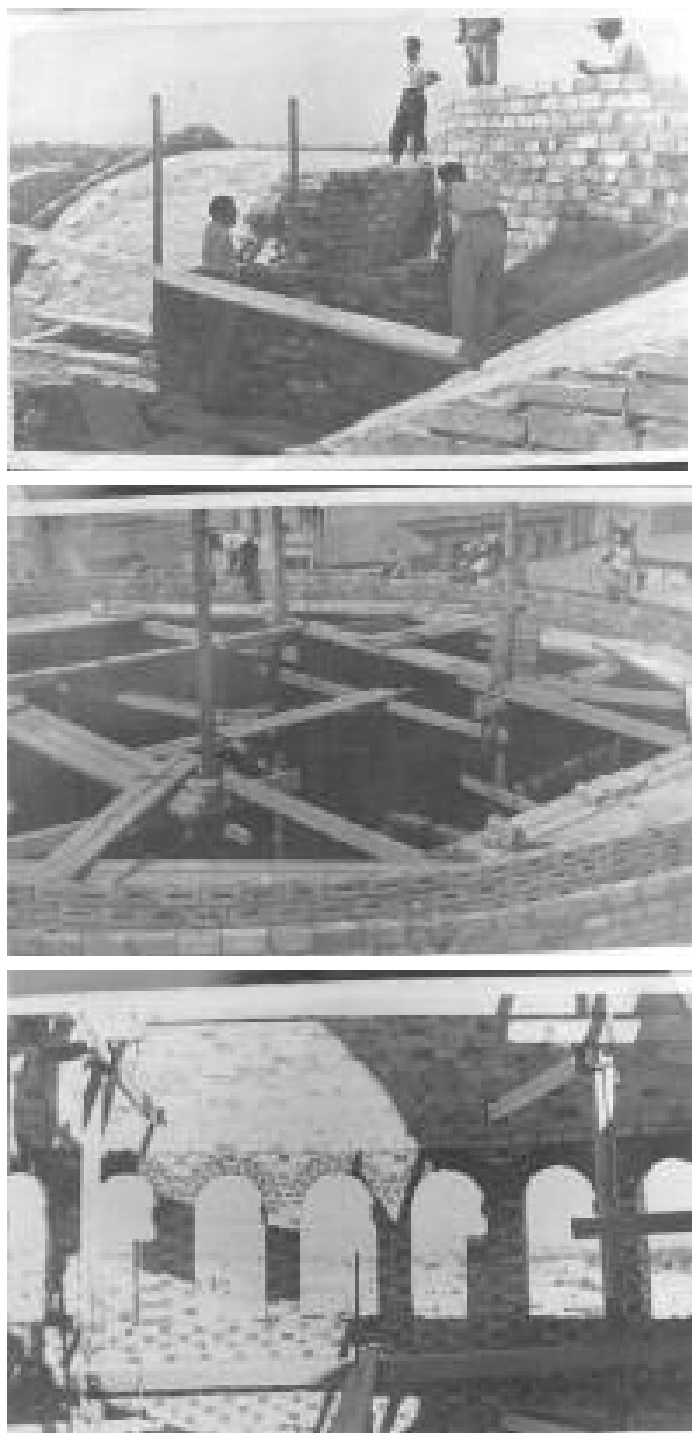

Fig. 5. Construcción de la cúpula bizantina de la Iglesia (F5.1y F5.2) y arcos de iluminación de la nave (F5.3). Fuente: colección Antonio Serrano Bru

Respecto al campanario indicar que tiene una estructura independiente del resto de la nave, formada por pilares de ladrillo zunchados entre sí por anillos del mismo material. Además su planta forma un octaedro regular en cuyo interior se encuentra una escalera de caracol que da acceso a su parte superior.

La construcción continuó combinando hábilmente soluciones volumétricas y de composición. La cubrición de la nave se resolvió con bóvedas de cañón corrido en los brazos de la cruz y con una cúpula bizantina en el crucero.Para que una vez realizados los arcos torales y bóvedas de cañón corrido, se pudiese proceder a la ejecución de las pechinas, de esta forma se podía pasar de una planta cuadrada a una circular, materializándose una cúpula bizantina rebajada en 
el crucero que se resolvió con ladrillo hueco de $3 \mathrm{~cm}$ (ver p.e.fig.5).

Por ello, con la finalidad de absorber el empuje horizontal de la cúpula, se construyó un anillo de hormigón armado de 350 kgsobre el anillo toral de fábrica de ladrillo hueco armado de $300 \mathrm{~kg}$, y sobre éste se colocaron unas ventanas resueltas mediante arcos de ladrillo de medio punto concéntricos, para permitir la iluminación de la nave. Una vez acabada la estructura, se procedió a ejecutar la cubrición de la misma para su remate final según la tradición levantina y mediterránea. Para ello el arquitecto realizó previamente el cálculo de las cargas de la misma obteniendo que el peso total de la cúpula era de $173.556 \mathrm{~kg}$, el cual sería absorbido por los 4 arcos que lo conformaban ${ }^{25}$.

En cuanto a la cubierta se solucionó mediante faldones a dos aguas sobre las bóvedas de cañón corrido. Las tejas curvas encarnadas se colocaron mediante tabiquillos de ladrillo cerámico hueco mediante regladas de mortero de cemento y cal hidráulica de $35 \mathrm{~cm}$, en la cúpula,y de $40 \mathrm{~cm}$ en las ventanas planas para formar la solera de ladrillo sobre la que se asentaba. Como remate en la cúpula se dispuso además una cruzveleta con una terminación de pararrayos.Asimismo, se construye una cubierta de teja sobre los triángulos de los riñones y pechinas de los arcos torales que rematan las cuatro construcciones en forma de torres prismáticas cercadas por paredes intermedias.

Por otro lado, la torre campanario y las zonas entre los brazos de la cruz se solucionan mediante cubiertas planas, con cerámica armada y hormigón hidráulico, que recogen el agua mediante cazoletas que vierten el agua en bajantes interiores.

Posteriormente se procedió a la ejecución de los revestimientos exteriores con mortero de cemento y la ejecución de los rosetones. Cabe mencionar, también, que dicho revestimiento se maestreó para permitir realizar finalmente un estuco a la catalana para su terminación.

\section{Conclusión}

La Iglesia del Sagrado Corazón de Jesús del arquitecto D. Antonio Serrano Peral es una obra religiosa que destaca por su resolución espacial y por su capacidad de integración volumétrica con el palmeral.

El proyecto se desarrolló bajo la sobriedad de una arquitectura de volúmenes ligeros con geometrías puras que denota la arquitectura racionalista del momento de su construcción. Además la precariedad económica del momento de su edificación, post-guerra española, hizo que se construyera con medios materiales muy sencillos, de ahí la esbeltez exterior y humildad arquitectónica que presenta.El hecho de utilizar el tradicional contrarresto de los arcos por los propios muros, disminución de anchura y altura, de las naves en cruz permitió construir los contrarrestos del edificio sin ser vistos desde el exterior.

Tras el estudio del cálculo de las cargas de la cubierta, del cálculo de los arcos del crucero y, de la carga acumulada en el riñón de la bóveda y el empuje de la bóveda tabicada sin refuerzo de costilla, el arquitecto con muy buen criterio y conocimiento del tema, procedió a la utilización del hormigón armado para solventar y contrarrestar los empujes horizontales que sobre ellos gravitaban a los apoyos, quedando las bóvedas tabicadas de ladrillo hueco como elemento estructural.Sin embargo, indicar que la desacertada solución constructiva del zuncho de atado perimetral del tambor con hormigón armado ha propiciado un movimiento por empuje estructural de la cúpula que se reflejan en la actualidad en una serie de grietas que, según testigos, han aumentado recientemente en su longitud.

\section{Agradecimientos}

A D. Antonio Serrano Bru por permitir consultar y utilizar documentos originales del archivo privado de D. Antonio Serrano Peral.

$\mathrm{Al}$ párroco D. Jesús Franco Martínez por permitir consultar y utilizar documentos originales del archivo de la Parroquia del Sagrado Corazón de Jesús de Elche.

25 Archivo del Arq. D. Antonio Serrano Peral. 